\title{
Contribuição para o estudo dendrológico e anatômico da madeira de três espécies de Qualea (Vochysiaceae) da Amazônia
}

\author{
Arthur A. Loureiro (") \\ Marlene Freitas da Silva (*)
}

\begin{abstract}
Resumo
Os autores apresentam o estudo de 3 espécies euxilóforas da Amazônia, pertencentes ao gênero Qualea (Vochysiaceae) - Q. albiflora, Q. cassiquia. rensis e Q. paraensis. Para cada espécie são apresentadas as seguintes indicações: a) da árvore caracteres botânicos gerais, habitat, ocorrência geográfica, nomes vulgares e fenologia; b) da madeira - caracteres gerais, descrição macro e microscópica, 3 macro e 6 microfotografias do lenho, 3 estampas esquemáticas das diferentes formas dos elementos vasculares encontrados nas espécies, um quadro das principais características anatômicas diferenciais das espécies e usos comuns
\end{abstract}

\section{INTRODUÇÃo}

O presente trabalho é uma contribuição эo estudo anatômico macro e microscópico de 3 espécies do gênero Quaiea da Amazônia. Como as madeiras dessas espécies são semelhantes no aspecto geral, tornou-se prática em toda Amazônia denominá-las pelo mesmo nome vulgar mandioqueira. Por tal motivo, o nosso interesse é fornecer cientificamente a classificação dessas espécies de real importância econômica regional, visto que em Manaus e em Belém elas são largamente usadas para vários fins, como: construção civil e naval (canoas), marcenaria, moirões e esquadrias.

Vários autores destacaram o interesse tecnológico e econômico do gênero: Paul Le Cointe (1947), afirma que a madeira de várias espécies tem real valor econômico na construção de embarcações, marıenaria, caixas e pasta para celulose; Record (1949) diz que a madeira de várias espécies possui real valor econômico, sendo usada em: carpintaria, construções internas, canoas, etc., muito semelhante ao Cedro (Cedrela); Loureiro \& Silva (1968) mencionam espécies: Qualea acuminata Ducke, $Q$. paraensis Ducke e Q. homosepala Ducke, para esquadirias, compensados, canoas, caixas e muito usadas em construção civil; Mainieri (1971) salienta o uso de Q. albiflora Warm, em marcenaria e caixotaria.

Algumas observaçōes sobre as propriedades $t$ empregos das Vochysiaceae foram ressaltadas por Löefgren (1917), principalmente com referência ao gênero Qualea. Outros estudos do ponto de vista madeireiro sobre algumas espécies da família, foram feitos por Bertin (1920), Kissin (1952), Bastos (1930), Bena (1960) e possivelmente outros, mencionando observações de interesse tecnológico e econômico de várias espécies.

Quanto a sua incidência geográfica, o gênero Qualea tem seu centro de distribuição na Hiléia, estendendo-se segundo Stafleu (1953) continuamente ao Norte até o Panamá.

Taxonomicamente, segundo aquele autor (I.c), as espécies: Qualea albiflora e Qualea cassiquiarensis pertencemı à Secção Trichantera do Subgênero Qualea, e Qualea paraen. sis à Secção Qualea deste mesmo Subgênero.

\section{Material e método}

O material estudado encontra-se registrado e depositado no Herbário e Xiloteca do INPA, com as seguintes indicações:

1 - Qualea albiflora Warm.

Brasil-Estado do Amazonas. Manaus. Reserva Florestal Ducke: A. Loureiro s/n fl (INPA $16184 \mathrm{X}$ - 3371); Estrada Manaus-Itacoatiara, $\mathrm{Km}$ 55: W. Rodrigues \& L. Coêtho 1836 fl (INPA 8208, X - 795); ibid., Km 125: W. Rodrigues 7410 fl (INPA 16812); Estrada Manaus-Caracaraí, Km 22: W. Rodrigues \& L. Coêlho 1939 fr. (INPA 8311, X -830 ). Rio Puciari.

(") - Instituto Nacional de Pesquisas da Amazônia, Manaus. 
afluente do rio Ituxi: G. Prance et al. 13815 fl (INPA 32031); Município de Maués: A. Ducke s/n fl (INPA 15554).

- Est. Pará. Belém: Bosque Municipal: M. Pires 2629 fl (INPA 2813); Reserva Florestal de Curuá-Una: Tressel 5 fl (INPA 14262).

2 - Qualea cassiquiarensis Spruce ex Warm. Brasil - Est. Amazonas. Manaus. Igarapé do Bindá: W. Rodrigues \& J. Chagas 2814 fl (INPA 10164); Parque 10 de Novembro: J. Chagas $\mathbf{s} / \mathbf{n}$ fr (INPA 3394); Igarapé do Buião: L. Coêlho s/n fr (INPA 6330; X - 688); Beira do Mindu: A. Ducke s/n fl (INPA 15580); Estrada Manaus-Caracaraí $\mathrm{Km}$ 124: I. Araújo, et al. $283 \mathrm{fr}$ (INPA 55067); ibid., Km 13c: D. Coêlho et al. S/n fr (INPA 62204); ibid., D. Coêlho \& M. Pereira s/n (INPA $\mathrm{X}-6353$ ); ibid.: D. Coêlho et al. 715 fl (INPA 54253, $X-6352$ ); ibid.: ibid. (INPA $\mathrm{X}-6354$ ).

3 - Qualea paraensis Ducke

Brasil - Est. Amazonas. Manaus. Estrada do Aleixo, $\mathrm{Km} \mathrm{3}$, Sede do INPA: W. Rodrigues 9532 fl (INPA 44585); W. Rocirigues \& A. Loureiro 7177 fl (INPA 15902); Estrada Manaus-Itacoatiara $\mathrm{Km}$ 79: W. Rodrigues 8160 est. (INPA 17521; X - 3589); Tgarapé Sempre Viva: E. Ferreira 102/57 fl (INPA 5850, X - 664); Reserva Florestal Ducke: $F_{1}$ Ferreira 95/57 fl (INPA 5843): ibid.: W. Rodrigues $5527 \mathrm{fl}$ (INPA 14200 , X - 1126); ibid.: A. Loureiro $\mathbf{s} / \mathbf{n}$ fl (INPA 16144, $\mathrm{X}-3340$ ); ibid.: ibid. fl (INPA 16171, X - 3364); ibid.: J. Elias 414 fl (INPA 20770). Boca do Acre. Monte Verde: G. Prance et al. $2476 \mathrm{fl}$ (INPA 18017).

- Est. Pará. Mangabal: A. Ducke s/n fl (INPA 15618); Reserva Florestal de Curuá-Una: Tressel $2 \mathrm{fl}$ (INPA 14261); ibid.: Tressel $7 \mathrm{fl}$ (INPA 14260); ibid.: Tressel 12 fl (INPA 14259).

A descrição botânica das espécies foi baseada na monografia de Stafleu (1953). O habitat, a distribuição geográfica, nomes vulga. res e fenologia foram obtidos da literatura consultada e do material de herbário disponível no INPA.

Para as descrições macro e microscópicas do lenho, obedecemos as recomendações da Associação Brasileira de Normas Técnicas (1973).

O método empregado na preparação das lâminas para o estudo anatômico foi aquele comumente usado em xilologia. As lâminas esstão registradas e arquivadas no laminário do INPA, assim como todo o material botânico examinado.
$\mathrm{Na}$ mensuração das fibras, diâmetro tangencial dos poros, número de vasos por milímetro quadrado, altura dos raios em micra, número de raios por milímetro linear e comprimentc dos elementos vasculares, utilizamos o Projetor Universal UP - 360-T II Olympus com a objetiva $50 x$ e $100 x$, e escala de vidro com $0,5 \mathrm{~mm}$ de unidade mínima de graduação, equivalendo cada uma a 50 e $10 \mu \mathrm{m}$ com as respectivas objetivas.

1 - Qualea albiflora Warm., in Martius, FI. Bras, 13 (2):36.1875.

Qualea glaberrima Ducke, Arq. Jard. Bot. Rio de Janeiro I: 46, est. 17 e 19. 1915.

CARACTERES BOTÂNICOS - Árvore grande a mediana com os ramos jovens pubérulos, marrom-avermelhados, quando adultos glabros; córtex não esfoliativo, persistente; glândulas nectariferas ligeiramente proeminentes; pecíolo delgado, glabro, subcilindrico; folhas subcoriáceas, delgadas, obovadas ou subelíticas, ápice obtuso ou curtamente obtuso-acuminado, base aguda ou subobtusa; flores aromáticas, solitárias ou em cincínios com 2-3 flores, axilares ou em rácemos: ráque, pedicelos e parte externa do cálice subglabros, botões florais agudos ou acuminados; lóbulos menores do cálice agudos, ciliados, lóbulo com esporão ciliado; esporão delgedo, ligeiramente recurvado, clavado: pétala branca suborbicular, ápice truncado ou emarginado, base amarelo-alaranjada, glabra, exceto na base; estame com filete longo; antera ciliada, agudo-acuminada; estaminoides e pétalas rudimentares freqüentemente presentes; ovário seríceo; estilete glabro, enrolado em espiral, longo; fruto cápsula elipsóide, escura, rugosa de $3 \mathrm{~cm}$ aproximadamente de comprimento.

DISTRIBUIÇÃo GEOGRáFICA - No Brasil, foi assinalada no Amazonas (Manaus, e no Município de Maués); no Pará (Belém e Município de Santarém). Seg. Stafleu (1953) ocorre ainda na Guiana Francesa (Marcní), na Guiana (Esequibo) e no Suriname (Maroni).

навттAт - Encontrada nas florestas de mata de terra firme em solo argiloso. 
Nomes vULGares - Brasil: Mandioqueira, Mandioqueira lisa, Mandioqueira preta (Manaus); Mandioqueira lisa (Belém): Suriname: Kwarie, Gronfolae (Stafleu, 1953).

FENOLOGIA - No Amazonas (Manaus) a floração tem sido registrada em outubro e novembro.

\section{DADOS GERAIS SOBRE A MADEIRA}

\section{CARACTERÍSTICAS GERAIS}

Madeira moderadamente pesada $(0,65$ a $\left.0,75 \mathrm{~g} / \mathrm{cm}^{3}\right)$; cerne bege claro, ligeiramente rosado; alburno amarelo castanho, bem distinto do cerne; grã irregular textura grosseira insípida e inodora; não muito fácil de trabalhar, podendo receber acabamento atrativo devido apresentar uma superfície lisa e lustrosa. Casca grossa, persistente de cor predominantemente marrom, com manchas claras, variando do amarelo para branco, pouco áspera.

\section{DESCRIÇÃO MACROSCÓPICA}

Parênquima apenas visivel a olho desarmado, escasso, do tipo vasicêntrico e aliforme de aletas muito curtas de um só lado dos poros, outras maiores envolvendo alguns poros $\epsilon$ eventualmente associando-os em arranjos obliquos. Poros bem perceptíveis a simples vista, solitários predominantes com $67 \%$, múltiplos de $2 \cdot 3$, notando-se também pequenas cadeias radiais de até 5 poros; de pouco, a pouco numerosos, médios a grandes, vazios, alguns obstruidos por tilos. Linhas vasculares bem visiveis a olho nu, são longas, retas, contendo substáncias da cor do lenho. Raios no topo só visiveis com ajuda de lupa, apresentando uma boa distribuição na largura e espaçamento, um tanto numerosos, levemente sinuosos; na face tangencial são altos, baixos de distribuição irregular, na radial visiveis sem auxílio de lente. Camadas de crescimento demarcadas por zonas mais escuras de tecido fibroso. Canais secre. tores e máculas medulares não foram observados (Estampa 1 a).

\section{DESCRIȨÃO MICROSCÓPICA}

Vâsos de secção semicircular ou ligeiramente ovalada; de distribuiçăo relativamente unifor- me, parede de $3-5 \mu \mathrm{m}$, vazios, alguns com substância gomosa, amarelada, de muito pouco a pcuco numerosos, osciiando de $5-13$ por milímetro quadrado, maioria de 7-9, pequenos a grandes, diâmetro tangencial vai de $80-250 \mu \mathrm{m}$ predominando os de $140-220 \mu \mathrm{m}(81 \%)$, raríssimos de $280 \mu \mathrm{m}$ de diâmetro; predominantemente solitários com $67 \%$, múitiplos de $2 \mathrm{com}$ $13 \%$, de $3-4,15 \%$, notando-se pequenas cadeias radiais de 5 vasos; perfurações simples; pontuações intervasculares pequenas, abertura inclusa, alternas; elementos vasculares de lúmen amplo, muito pequenos a longos, oscilando entre $300-680 \mu \mathrm{m}$ de comprimento, predominando os de $410-500 \mu \mathrm{m} 46 \%$; apresentando apêndices muito curtos de um só lado, de am. bos os extremos e também raríssimos sem pre sença de apêndire de forma diferente conforme mostra o desenho esquemático (Fig. 1). Raios apresentando substância amarelada em todas suas células e aparentemente corpúsculos de sílica, irregularmente dispostos, heterogêneos a homogêneos, predominando os homocelula-
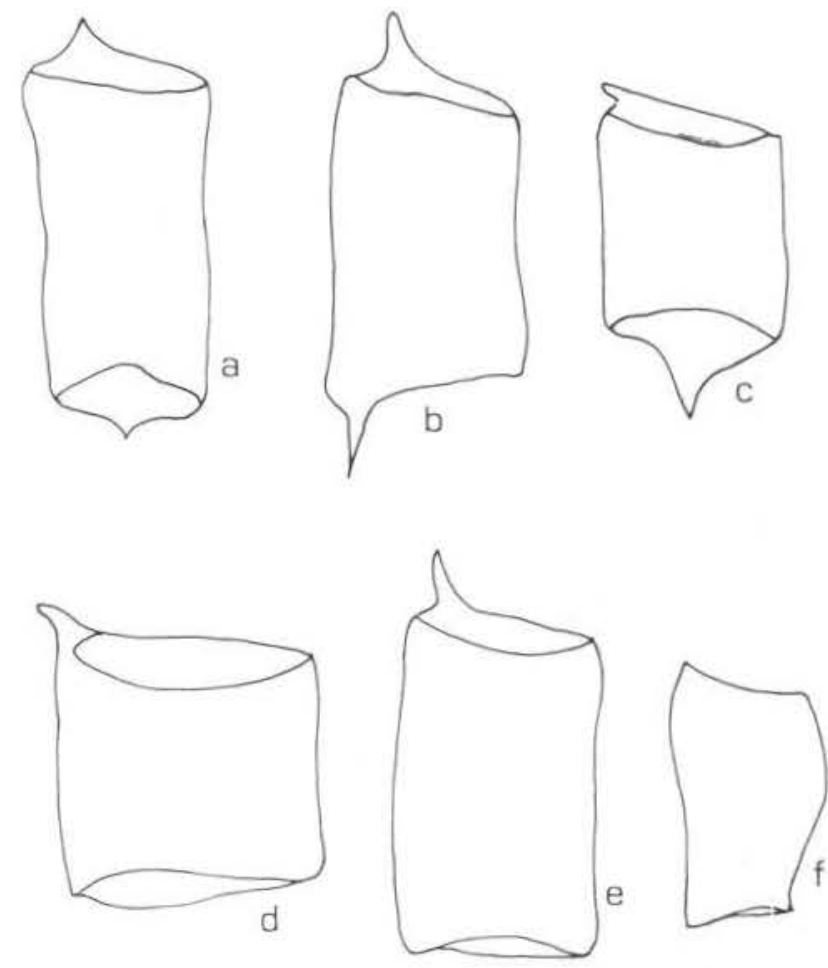

0 $0.7 \mathrm{~mm}$

Fig. 1 - Qualea albiflor ‘ Warm. Desenho esquemático das diferentes formas dos elementos vascula. res encontrados na espécie. ( $\mathrm{a}, \mathrm{b}, \mathrm{c}, \mathrm{d}, \mathrm{e}, \mathrm{f}$ ). 
res, de 2 - 3 células de largura, os bisseriados com $74 \%$, unisseriados com $19 \%$, os demais trisseriados; de extremamente baixo a muito baixos, maior ocorrência entre $160-480(88 \%)$ $\mu \mathrm{m}$ de comprimento, esporadicamente encontra-se de 600 ou até mesmo $800 \mu \mathrm{m}$ chegando a ter $4 \%$ de raios fusionados com uma altura de $520-800 \mu \mathrm{m}$ de comprimento; aitura em número de células apresenta uma variação de $3-25$ células, maioria entre $6-15(69 \%)$, raríssimos de 2 e 28 células de altura; os fusionados com 23 - 31 células, número de raios por milímetro linear varia de $4-9$, sua maior freqüência é 6 - $8(73 \%)$, ocasionalmente encontrando-se de 2 e às vezes até 11 por milímetro linear; pontuações radiovasculares do mesmo tipo das inter. Parênquima apotraqueal concêntrico largo, às vezes predominando e iigando alguns vasos, sendo muito freqüente o tipo intermediário, entre o paratraqueal vasicêntrico e o aliforme de aletas curtas ou alado confluente, raramente difuso em pequenos agrupamentos; seriado de $3-6$, com células largas e estreitas, maioria de $5-4$ células. Encontrando-se em grande quantidade nas células dos raios e do parênquima axial uma substância não identificada que provavelmente vem ser silica, nota-se também presença de cristais. Fibras libriformes de pontuações simples muito pequenas, areoladas de parede entre $6-8 \mu \mathrm{m}$ de lúmen maior, variando de $8-13 \mu \mathrm{m}$; elementos fibrosos de curtos a longos com $1000-1900 \mu \mathrm{m}$ de comprimento, maioria ocorre na faixa de $1210-700 \mu \mathrm{m}(74 \%)$. Camada de crescimento pouco delimitada, notando-se porém, de espaço a espaço, zonas estreitas de lenho mais compacto pelo achatamento das últimas fibras e pela presença dos parênquimas apotraqueai, muitas vezes duvidosas. Máculas medulares ausentes. (Estampa $1 \mathrm{~b}$ e $c$ ).

\section{USOS COMUNS}

Caixotaria, marcenaria, construções internas, canoas, tacos, coronhas de armas, caibros, pasta para celulose.

2 - Qualea cassiquiarensis Spruce ex Warm. in Martius, Fl. Bras. 13 (2): 34. 1875.

CARACTERES BOTÂNICOS - Árvore grande a mediana; ramos e folhas glabros; córtex escu- ro não esfoliativo; glândulas nectaríferas näo proeminentes, porém perfeitamente visiveis no caule, na base dos pecíolos; pecíolos espessos, glabros, rugosos, subcilíndricos; folhas rigidocoriáceas, oblongo-lanceoiadas, subelíticas ou suboblongas; ápice obtuso comumente mucro-
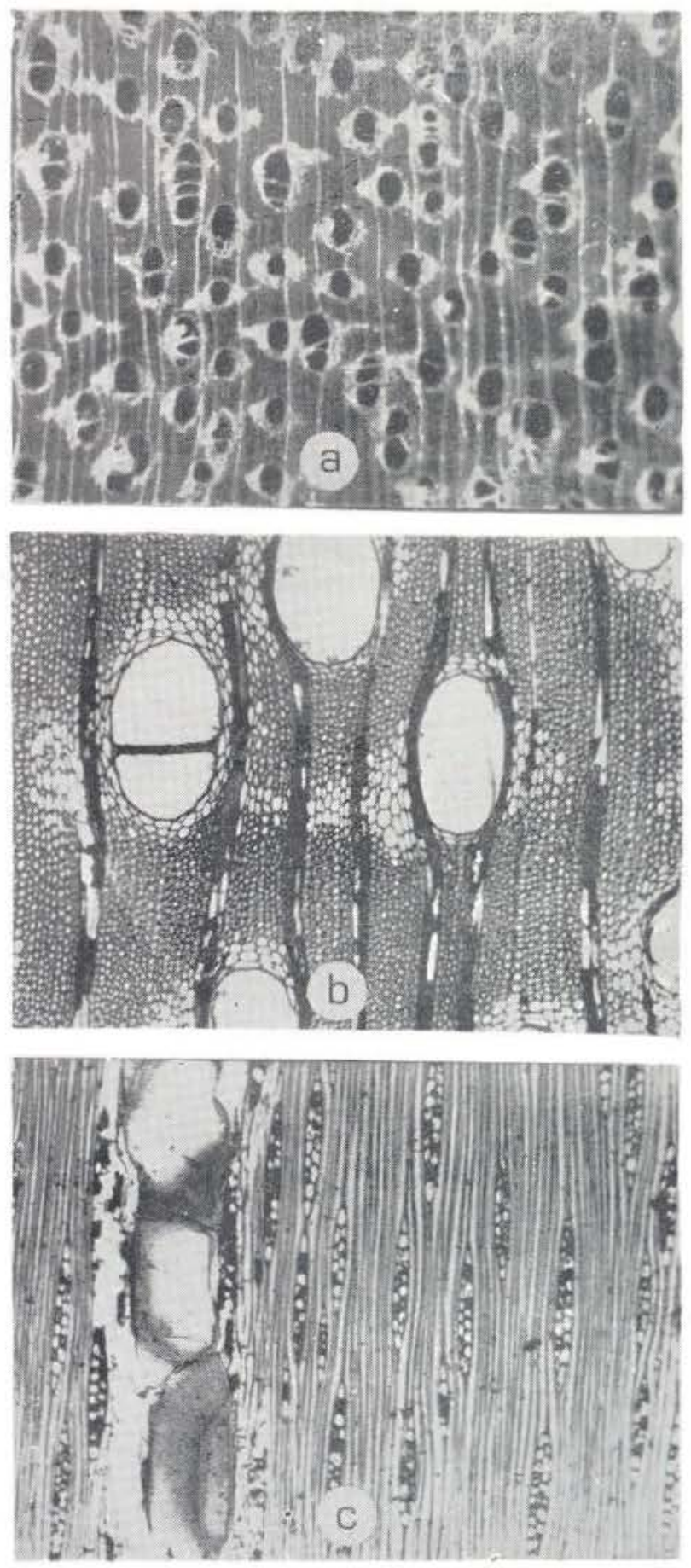

Est. 1 - Qualea albiflora Warm. a - Secção transversal $(20 \mathrm{X})$; b - Secçã̃o transversal ( $80 \mathrm{X})$; c Secção tangencial (80 X). 
nado, base obtusa ou cuneada; nervura mediana proeminente na face inferior, na superior submersa, tendo em geral em toda a extensão da folha uma fileira de pêlos que acompanha late. ralmente a nervura, no dorso; nervuras laterais numerosas, subproeminentes em ambas as faces; inflorescência pubérula em panícula terminal composta de 1 - 2 cincínios de flores; pedicelos delgados, longos; botões florais alongados, subcilíndricos, estreitos, ápice obtuso, mais espesso junto a base; flores aromáticas: cálice com os lóbulos menores subiguais, esporão espesso situado quase que na parte dorsal do lóbulo maior, estreitancio-se ao longo do pedicelo, mais ou menos bursiforme; pétala (única) obcordata, com uma mancha amarelo-alaranjada no centro; antera longa, ciliada, longitudinalmente; filete glabro; estaminóide ausente; ovário ovóide amarelo lanuginoso (pêlos longos $2 \mathrm{~mm}$ ) em torno do estilete; estilete glabro alongado e recurvado; fruto cápsula elipsóide, septicida, lenhosa, deiscente, 3-valvar, superfície verrucosa, ápice acuminado com a base do estilete enrolado, persistente, base obtusa.

DISTRIBUYÇÃo GEOGRÁFICA - No Brasil, tem sido encontrada com relativa freqüência no Estado do Amazonas (Manaus). Ocorre também na Amazônia venezuelana, segundo Stafleu (1953) .

HABItAT - Matas ciliares próximos de igarapés em lugares úmidos, não inundáveis.

FENOLOGIA - Em Manaus (Amazonas) floresce em outubro a novembro para frutificar em janeiro até março.

\section{DADOS GERAIS SOBRE A MADEIRA}

\section{CARACTERÍSTICAS GERAIS}

Madeira pesada $\left(0,70-0,85 \mathrm{~g} / \mathrm{cm}^{3}\right)$. Casca persistente de cor predominante marrom com manchas claras, superfície áspera, apresentando pequenos sulcos longitudinais e uma espessura entre 5-7 milimetros. Cerne bem desenvolvido, creme de aspecto róseo; alburno levemente diferenciado do cerne com tonalidade amarelada; grã irregular para direita; textura grosseira e áspera ao tato; insípida e ino- dora. Um tanto difícil de trabalhar, porém. recebe bom acabamento com polimento atrativo devido a sua tonalidade brilhosa na superfície.

\section{DESCRIÇÃo MACROSCÓPICA}

Parênquima relativamente escasso, apenas visível a simples vista, envolvendo os poros, formando aréolas de largura estreita, circular em forma vasicêntrica e aliforme de expansões curtas, às vezes associando alguns poros. Poros visíveis a olho nu, pequenos a mécilos, so. litários predominantes com $64 \%$, geminados de $2-3$, pequenas cadeias radiais até $4-5$ poros, en: associação com o parênquima forma arranjos oblíquos e diagonais, vazios, alguns obstruídos por tilos da cor do lenho. Linhas vasculares bem perceptíveis sem auxílio de lente, retas, longas, contendo substâncias da cor da madeira. Raios no topo visíveis a simples vista, numerosos, finos, pouco sinuosos, contínuos e interrompidos, apresentando boa uniformidade na largura e espaçamento; na face tangencial são irregularmente distribuídos, baixos; na radial são contrastados, bem perceptiveis sem ajuda de lente. Camadas de crescimento apenas delimitada por zonas mais escuras de tecido fibroso, às vezes contínuas. Canais secretores e mácuias medulares não foram observados. (Estampa 2 a).

\section{DESCRIÇÃO MICROSCÓPICA}

Vasos de secção ovalada a semicircular, de parede fina a média entre $3-8 \mu \mathrm{m}$ de espessura, distribuição um tanto uniforme, médios a grandes, variando de $110-260 \mu \mathrm{m}$ de diâmetro tangencial, maioria ocorre na faixa de 170-250 um $(69 \%)$, encontrando-se esporadicamente de 80 e às vezes até 290 , vazios, alguns obstruídos por tilos; de pouco numerosos a numerosos 6- 12 por milimetro quadrado, mais assiduamen. te de 8-9; solitários predominantes com $53 \%$, múltiplos de $2 \mathrm{com} 35 \%$, de 3 e $4 \mathrm{com} 12 \%$, pontuações intervasculares, areoladas, inclusa, alternas. pequenas, guarnecidas; elementos vasculares de curtos a muito longos entre $400-900 \mu \mathrm{m}$ de comprimento, mais comum de 400-700 um (78\%) excepcionalmente chega $1150 \mu \mathrm{m}$ de comprimento, apresentando apêndice de ambos os lados ou de um só lado e também sem apêndice nos extremos, sendo es- 
tes apêndices comumente, curtos e em casos raros atingem até a metade do elemento vascular, de formas bem diferentes, conforme vemos no desenhe esquemático (Fig. 2). Raios heterocelulares e homocelulares, dispostos irregularmente, bisseriados predominantes com $76 \%$, uni e trisseriados; de extremamente baixos a muito baixos, maioria ocorre entre 270-480 $\mu \mathrm{m}$ $(72 \%)$, encontrando raios fusionados na proporção de 5\%, com uma altura de $430-610 \mu \mathrm{m}$ de comprimento; altura em número de células varia, de 5-35, maior freqüência de 110-250 células $(86 \%)$; os fusionados aparecem com $12 \%$ da totalidade e de 16-29 células, comumente na íaixa de 21 - 25 células de altura; número de raios por milímetro linear variando entre $3-8$, sobressaindo os de $5-6(60 \%)$, ocasionalmente podemos encontrar até 9; pontuaçōes radiovasculares do mesmo tipo das intervasculares, um pouco maiores. Parênquima axial, relativamente escasso, paratraqueal e apotraqueal, do tipo intermediário entre alado ou unilateral e aliforme de expansões laterais simples, às vezes incompleto, associandio 2 ou mais vasos, ocorrendo também o circunvascular; seriado com 3-4 e até 7 células por série. Exclusivamente nas células dos raios, vista com mais intensidade nos cortes transversal e radial, há grande quantidade de uma substância não identificada, possivelmente silica. Fibras de pontuações simples e indistintamente areoladas, médias, diâmetro do lúmen oscilando entre 5.4-16 $\mu \mathrm{m}$ sua espessura não ultrapassa 5.4- $3 \mu \mathrm{m}$ com uma variação de 1 - 4 septos, notando-se rarissimas de 5 e às vezes com ausência de septos; elementos fibrosos de curtos a longos com 1100-1600 $\mu \mathrm{m}$ de comprimento, maior incidência de 1210-1400 $\mu \mathrm{m}$ (44\%), esporadicamente encontra-se de 900 e até mesmo $1700 \mu \mathrm{m}$. Camadas de crescimento demarcada por zonas de camadas fibrosas mais compacta e de parede mais grossa e de lúmen achatado, muitas vezes freqüentemente duvidosas, em alguns casos aparecem perfeitamente perceptíveis, devido o achatamento tangencial das fibras do lenho tardio e também por causa da fistulosidade das fibras do fim de um anel e do início do seguinte. Máculas medulares e canais intercelulares não foram observados. Si nais de estratificaçăo, ausentes (Estampa 2 $a \mathrm{e} b)$.
USOS COMUNS

Construções internas, canoas, carpintaria, caixas.
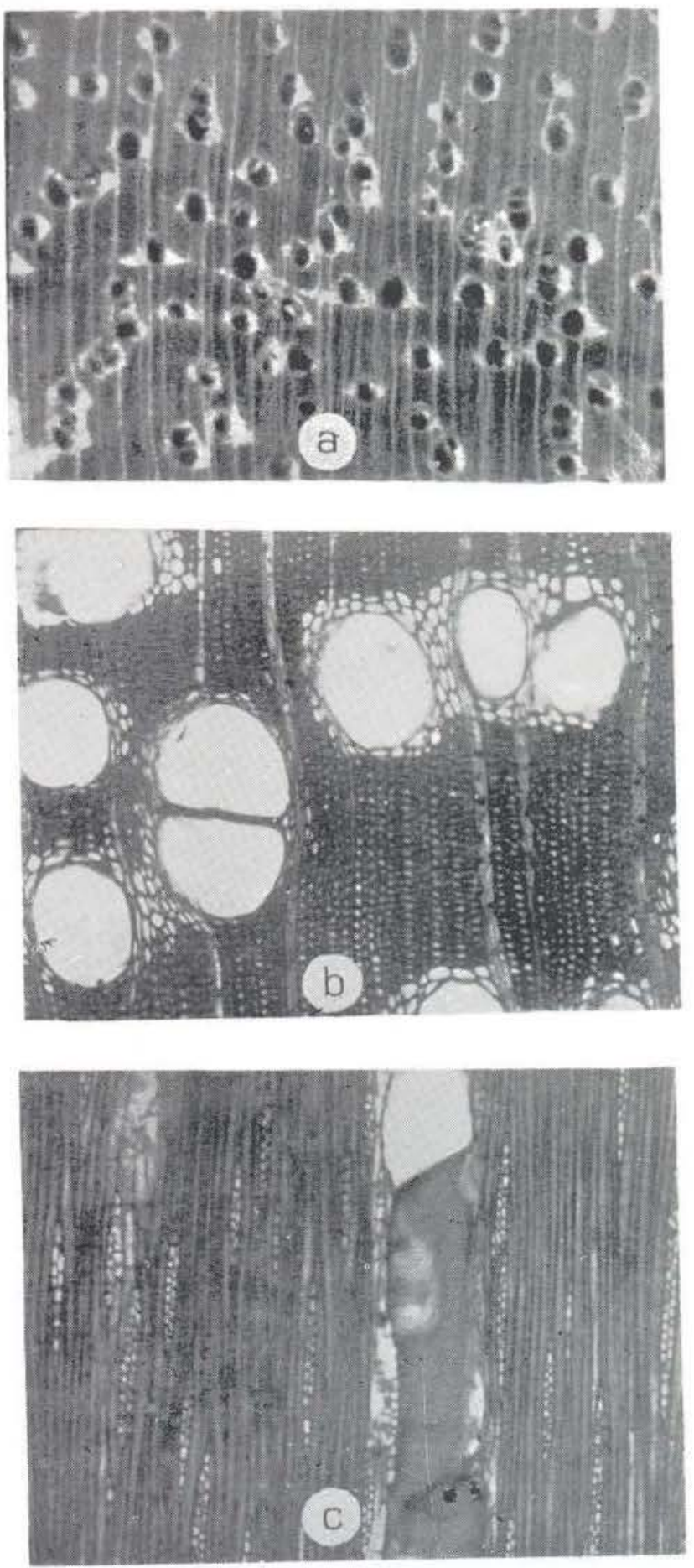

Est. 2 - Qualea cassiquiarensis Spruce ex Warm. a - Secção transversal ( $20 \mathrm{X}) ; \mathrm{b}$ - Secção transversal $(80 \mathrm{X})$; c - Secção tangencial (80 X). 


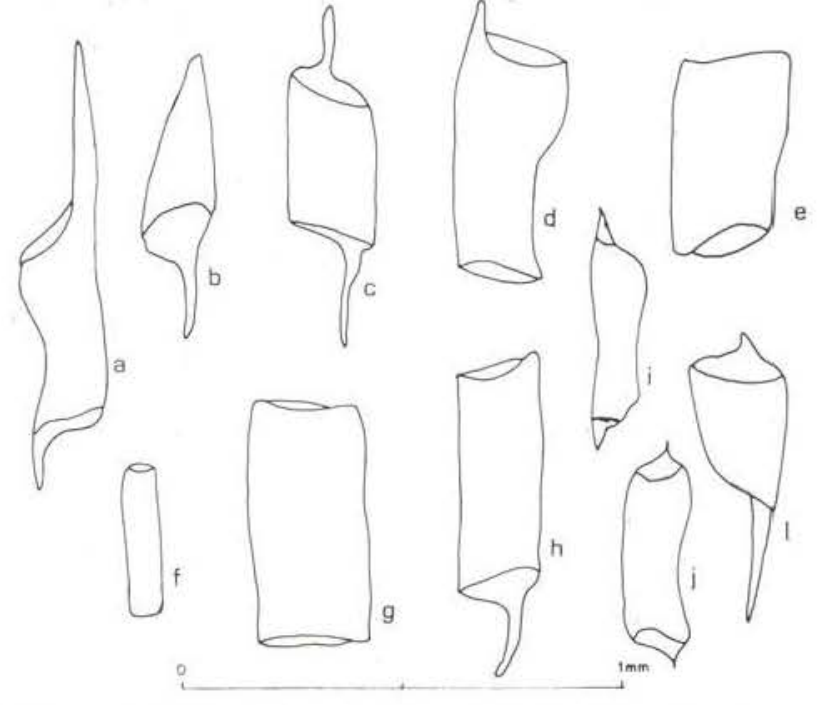

Fig. 2 - Qualea cassiquiarensis Spruce ex Warm. Desenho esquemático das diferentes formas dos elementos vasculares encontrados na espécie. ( $a, b$, c, d, e, f, g, h, i, j, 1).

3 - Qualea paraensis Ducke, Arq. Jard. Bot. Rio de Janeiro 1: 44, est. 16. 1915.

CARACTERES BOTÂNICOS - Árvore grande, córtex dos ramos jovens esfoliativo; nectários extraflorais axilares, urceolares; pecíolo subcilíndrico, glabro, finamente canaliculado na parte superior; folhas coriáceas, oblongas ou elítico-oblongas, ápice acuminado, base aguda ou obtusa, glabras, lustrosas nas face superior, na inferior opacas com alguns pêlos junto à nervura mediana; nervuras laterais numerosas (8-15) por $\mathrm{cm}$, salientes nas 2 faces; inflorescência em panículas terminais freqüentemente com 2 flores em cincínio; pedicelos delgados, longos, puberulentos; flores aromáticas; cálice seríceo externa e internamente nos lóbulos; lóbulos arredondados, sendo o lateral menor do que o anterior; esporão elipsóide; pétala branca, arredondada, com a base vermelha e o centro amarelo; pétalas rudimentares presentes; estames com filete glabro, antera lanceolada, sub-rocurvada, com o dorso piloso, ápice arredondado, emarginado; estaminóides presentes; ovário globoso, densamente piloso com estilete subglabro; estígma semilateral, não capitado: fruto sápsula desconhecida.

DISTRIBUIÇÃO GEOGRÁFICA - No Brasil, tem ampla distribuição na Amazônia brasileira nos Estados do Amazonas, Pará, Acre e Mato Grosso, ocorre ainda na Guiana e seg. Stafleu (1953) na Colômbia, em Uaupés, e, no rio Maranon (Peru Amazônico) .

HABITAT - Comumente encontrada nas ma. tas de terra firme e ocasional na margem de igarapés.

NOMES VULGARES - Brasil: Mandioqueira, Mandioqueira vermelha, Quaruba (!) (Manaus e arredores); Mandioqueira escamosa, Lacreiro (Pará, Santarém); Mandioqueira (Acre).

FENOLOGIA - Em Manaus (Amazonas) a floração vai de setembro a novembro.

\section{DADOS GERAIS SOBRE A MADEIRA}

\section{CARACTERÍSTICAS GERAIS}

Madeira pesada $\left(0,70\right.$ a $\left.0,80 \mathrm{~g} / \mathrm{cm}^{3}\right)$; cerne bege claro amarelado ou levemente rosado; alburno amarelado bem demarcado do cerne; grá irregular; textura grosseira; cheiro e gosto indistintos. Boa de trabaihar, recebendo bom acabamento. Casca grossa, rugosa, escura, com manchas esbranquiçadas, áspera, persistente.

\section{DESCRIÇÃO MACROSCÓPICA}

Parênquima abundante, apenas visivel a olho nu, aliforme, de expansões curtas e longas, chegando a formar arranjos obliquos ligando alguns poros, destacando-se as faixas terminais, largas, afastadas e às vezes associadas. Poros visíveis a olho desarmado, pouco numerosos, médios a grandes, solitários, agrupados em 2-3 poros, vazios, alguns obstruidos por tilos. Linhas vasculares notadas a olho nu, um tanto retas e longas. Raios no topo são finos e numerosos, visíveis sob lente, bem uniformes na largura; na face tangencial apresentam-se curtos e irregularmente distribuídos; na face radial são contrastados. Camadas de cresct mento indistintas. Máculas medulares não fo ram observadas. Canais secretores verticais, em séries, delimitando também a camada anual em associação com o parênquima (Estampa 3 a).

\section{DESCRIÇÃO MICROSCÓPICA}

Vasos de parede entre 5-8 $\mu \mathrm{m}$ de espes. sura, secção oval e circular, distribuição difusa; 
médios a orandes variando de $110-250 \mu \mathrm{m}$ de diâmetro tangencial, mais assiduamente na fai$x a$ de $140-250(88 \%)$, dificilmente encontra-se de 100 e até mesmo $290 \mu \mathrm{m}$ totalmente vazios; de muito poucos a pouco numerosos $4-10$ por milímetro quadrado, mais freqüentemente os poucos entre a faixa de 6 - 8 por milimetro quadrado: predominantemente solitários $(60 \%)$. múltiplos de $2-3,(32 \%)$ os demais em pequenas cadeiras radiais de $4-5$ vasos; placas de perfurações simples; pontuações intervasculares guarnecidas, alternas, areoladas, abertura inclusa, pequenas a grandes; elementos vasculares de lúmen amplo, curtos a longos $350-90 \mathrm{C}$ de comprimento mais freqüente de $510-700$ $(52 \%)$, às vezes encontra-se até $950 \mu \mathrm{m}$ apresenta apêndice curtos de ambos os extremos, mais freqüentemente de um só lado, ocasionalmente alguns sem presença de apêndice, de forma variada conforme são observados no desenho esquemático (Fig. 3). Raios heterocelulares a homocelulares, irregularmente distri-
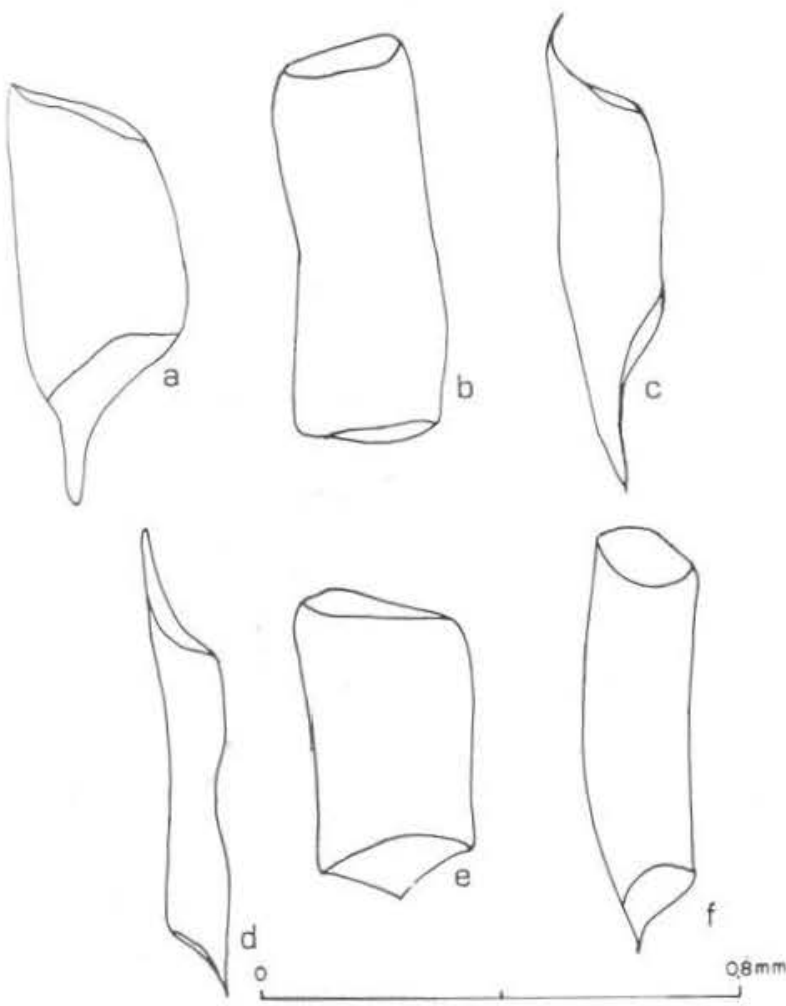

Fig. 3 - Qualea paraensis Ducke. Desenho esquemático das diferentes formas dos elementos vasculares encontrados na espécie ( $a, b, c, d, e, f)$. buídos, trisseriados predominantes $(40 \%)$, bisseriados $(28 \%)$, unisseriados $(18 \%)$ ou demais com 4 células de largura; extremamente baixos a muito baixos, oscilando de $50-960 \mu \mathrm{m}$ de comprimento, predominando os de $50-370 \mu \mathrm{m}$ $(47 \%)$ chegando a ter $4 \%$ de raios fusionados
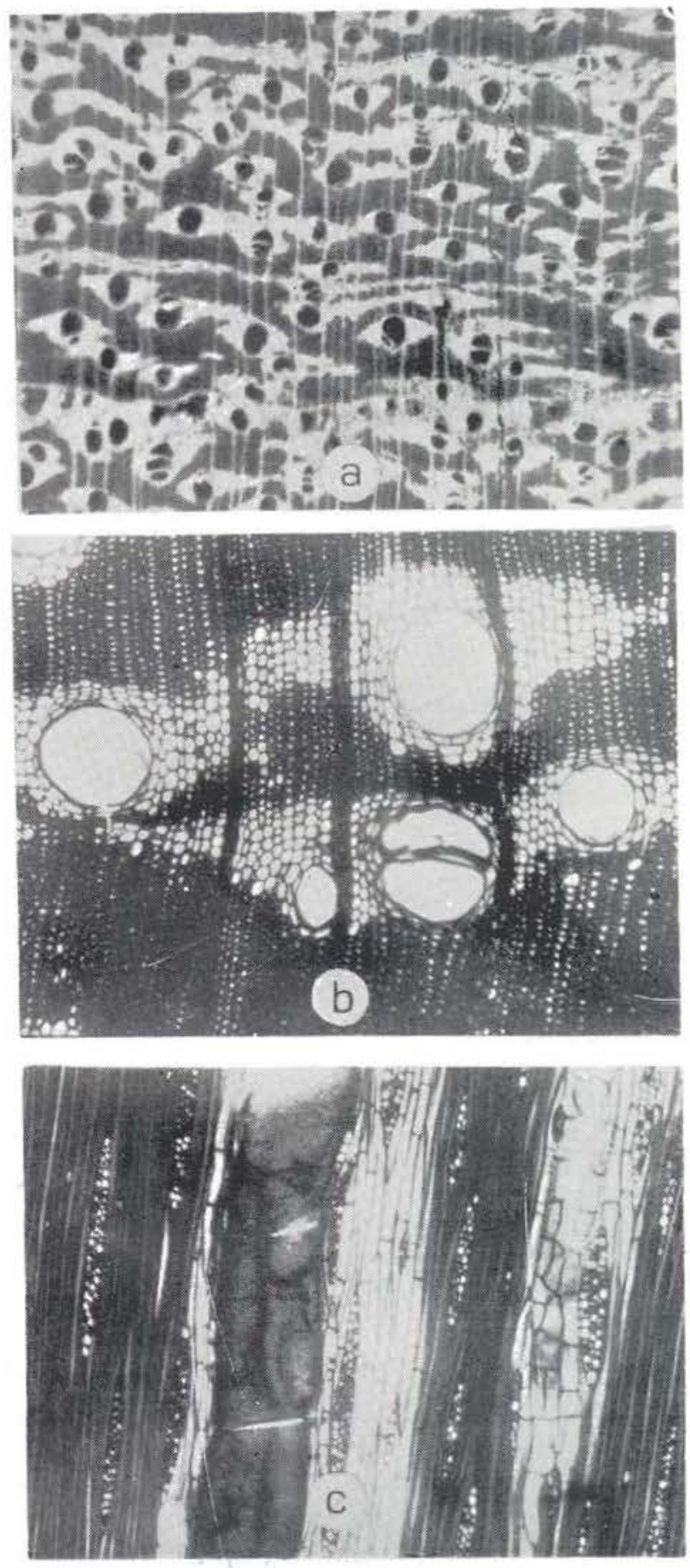

Est. 3 - Qualea paraensis Ducke. a - Secção transversal (20 X); b - Secção transversal (80 X); c - Secção tangencial ( $80 \mathrm{X})$. 
com uma altura de 720 - $980 \mu \mathrm{m}$ de comprimento; altura em número de células é muito variável, encontrando-se no mínimo de 1 e no máximo 65 células de altura, mais freqüentemente de 1 - 25 células, entre os fusionados chega a ter 54 - 64 células; número de raios por milímetro linear fica entre 2-7, esporadicamente encontramos até 8 , sendo sua maior freqüência em $73 \%$ entre os de 3 - 5 raios por milímetro linear: pontuaçōes radicvasculares, maiores que as intervasculares, porém, do mesmo tipo. Parênquima axial abundante, paratraqueal, confluente, formando faixas concêntricas, afastadas, onduladas, regulares para irregulares com 3 - 12 células de altura ligando e envolvendo os vasos, outras interrompidas, também o aliforme de aletas curtas e largas, raríssima presença do apotraqueal; seriado de 3 - 6 , comumente com 4 células por série. Nas células dos raios, vista em todos os cortes, nota-se também a presença de substâncias gomosas, e possivelmente silica em abundância. Fibras libriforme de pontuações simples, médias, diâ. metro do lúmen de $3-5 \mu \mathrm{m}$ espessura da parede oscila de 5 - $11 \mu \mathrm{m}$ de 1 - 2 septos, às vezes sem presença de septos; elementos fibrosos de curtos a longos, mínimo de 1010 e máximo de $1890 \mu \mathrm{m}$ de comprimento, maior freqüência na faixa de 1210 - $1700(74 \%)$. Camadas de cres. cimento demarcadas por zonas fibrosas escuras, de células de parede compactas e lúmen achatado às vezes sem presença do parênquima axial. Máculas medulares ausentes. Canais secretores ou gomosos verticais de origem traumáticos, presentes (Estampa $3 b$ e c).

\section{USOS COMUNS}

Compensado, caixas, remos, canoas, esquadrias: construção civil.

\section{DISCUSSÃO}

Além das características morfológicas apresentadas nas descriçōes taxonômicas, a madeira destas espécies apresenta as seguintes diferenciações anatômicas:

PRINCIPAIS CARACTERES ANATOMMICOS DIFERENCIAIS DO LENHO DAS ESPÉCIES ESTUDADAS

\begin{tabular}{|c|c|c|c|}
\hline & $\begin{array}{l}\text { Qualea } \\
\text { cassiquiarensis }\end{array}$ & $\begin{array}{l}\text { Qualea } \\
\text { albiflora }\end{array}$ & $\begin{array}{c}\text { Qualea } \\
\text { paraensis }\end{array}$ \\
\hline Peso cientifico $\left({ }^{*}\right)$ & $0.70-0,85$ & $0,65 \cdot 0,75$ & $0,70 \cdot 0,80$ \\
\hline Cor (cerne) & Creme de aspecto róseo & Bege claro rosado & Levemente rosado \\
\hline Cor (alburno) & Amarelado & Amarelo castanho & Amarelado \\
\hline Poros : & & & \\
\hline $\begin{array}{l}\text { Classificação } \\
\text { Raios : }\end{array}$ & $\begin{array}{l}\text { Solitário predominante } 53 \% \text {, } \\
\text { múltiplos } 2-3,35 \% \text { e } 3-4 \text {, } \\
12 \% \text {. }\end{array}$ & $\begin{array}{l}\text { Solitários predominantes } \\
67 \% \text {; múltiplos de } 2-4 \text {, } \\
28 \% \text {, rarissimas cadeias } \\
\text { radiais. }\end{array}$ & $\begin{array}{l}\text { Solitários predominantes } 60 \% \text { : } \\
\text { múltiplos } 2-3,32 \% \text { e } 28 \% \text { de } \\
\text { cadeias radiais. }\end{array}$ \\
\hline Tipos & $\begin{array}{l}\text { Heterogêneos e homogê- } \\
\text { neos }\end{array}$ & $\begin{array}{l}\text { Homogêneos e heterogêneos } \\
\text { maioria homogêneos }\end{array}$ & Heterogêneos e homogêneos \\
\hline $\begin{array}{l}\text { Largura dos raios em } n^{\circ} \\
\text { de células }\end{array}$ & $\begin{array}{l}\text { Bisseriado } 76 \% \text {; unisseria- } \\
\text { do } 12 \% \text { e trisseriado } \\
21 \% \text {. }\end{array}$ & $\begin{array}{l}\text { Bisseriado } 74 \% \text {; unisseriado } \\
19 \% \text {; trisseriado } 7 \% \text {. }\end{array}$ & $\begin{array}{l}\text { Triss e r i a do } 40 \% \text {; bisse- } \\
\text { riado } 28 \% \text {; unisseriado } 18 \% \\
\text { e tetrasseriado } 14 \% \text {. }\end{array}$ \\
\hline $\begin{array}{l}\text { Raios por mm linear } \\
\text { Parênquima : }\end{array}$ & $\begin{array}{l}\text { De } 3-8 \text {, maioria entre } 5-6 \\
(60 \%)\end{array}$ & $\begin{array}{l}\text { De } 4-9 \text {, maioria entre } 6-8 \text {, } \\
(73 \%)\end{array}$ & De $2-7$ maioria entre $3-5(78 \%)$. \\
\hline Tipo & $\begin{array}{l}\text { Apotraqueal e paratraqueal. } \\
\text { Aliforme simples às vezes } \\
\text { liga } 2 \text { ou mais poros. } \\
\text { Vasicêntrico e alado. Das } \\
\text { espécies estudadas é a que } \\
\text { que possui mennr quanti- } \\
\text { dade de parênquima. }\end{array}$ & $\begin{array}{l}\text { Paratraqueal e apotraqueal. } \\
\text { Vasicêntrico e aliforme de } \\
\text { aletas curtas ou alado } \\
\text { confluente ainda difuso } \\
\text { em pequenos grupos. }\end{array}$ & $\begin{array}{l}\text { Paratraqueal, o c a sionalmente } \\
\text { apotraqueal. Muito abundan- } \\
\text { te, aliforme e em faixas lon- } \\
\text { gas bem largas, irregulares, } \\
\text { quase concêntricas, com } 3-12 \\
\text { células de altura. Das espé- } \\
\text { cies estudadas é a que pos- } \\
\text { sui maior quantidade de pa- } \\
\text { rênquima. }\end{array}$ \\
\hline
\end{tabular}

(*) - Madeira seca ao or $\left(\mathrm{g} / \mathrm{cm}^{3}\right)$ 


\section{AGRADECIMENTOS}

Expressamos os nossos mais sinceros agradecimentos aos acadêmicos de Engenharia Operacional da Universidade de Tecnologia da Amazônia (UTAM): Francisco Vasconcellos, Silene Pessoa, Lucia Tinôco, Daniel Ferreira e Rossini Batista, pela colaboraçăo que nos deram na parte de maceração e mensuração de todos elementos constituintes do lenho; também, ao desenhista Alberto Silva, e aos auxiliares técnicos Wilson Meirelles, Darlinda Bastos e Manoel Moacir Pereira.

\section{SUMMARY}

In the paper, a contribution to the dendrological knowledge of the Amazonian species of the family Vochysiaceae is given by the authors, by including botanical description, geographical distribution, habitat and anatomical description of wood of the following species: Qualea albiflora, Q. cassiquiarensis and $\mathbf{Q}$. paraensis. 9 illustrations of the woods described and a list of the principals anatomical characteristics are included in this paper.

\section{BIBLIOGRAFIA CITADA}

AsSociação brasiletra de Normas técnicas

1973 - Descrição dos caracteres gerais e anatômicos macro e microscópicos das madeiras de dicotiledôneas brasileiras. Rio de Janeiro. p. 18 (mimeografado).

Bastos, A.M.

1930 - As madeiras da Amazônia na indústria do papel. Bol. Esc. de Química Industrial. Belém $1: 80-83$.
BENA, P.

1960 - Essences forestières de Guyane. Paris, Bureau Agricole et Forestier Guayanais, Imprimerie Nationele. vi +188 p., 114 fig. 85 est. tab. (10 est. em anexo).

BERTIN, A.

1920 - Les bois de Guyane française et du Brésil. Paris, Mission d'Etudes Forestières, Ed. Emile Larose. 315 p. 23 fig. 2 est. (Prefácio de Lecomte; colaboração de M. Bettenfeld e R. Benoist).

KIssin, I.

1952 - A situação madeireira da Amazônia (um estudo preliminar). Bclém, Banco de Crédito da Amazônia, 180 p.

Le COINTE, $P$.

1947 - Amazônia brasileira - III. Árvores e plantas úteis (indígenas e aclimadas). 2 ed. São Paulo, Ed. Nacional. 506 p. 14 est. (Brasiliana, série 5.a, v. 251).

LÖEFGREN, A.

1917 - Manual das famílias naturaes phanerogamas. Rio de Janeiro. Imprensa $\mathrm{Na}$ cional. $611 \mathrm{~F}$.

LOUREIRo, A.A. \& SILVA, M.F. DA

1968 - Catálogo das madeiras da Amazônia. Belém. SUDAM. V. II, p. 347-364.

MAINIERI, C.

1971 - 25 madeiras da Amazônia de valor comercial, caracterizaçăo macroscópica, usos comuns e índices qualificativos. Publ. Instituto de Pesquisas Tecnológicas de São Paulo. p. 20-21.

RECORD, S.J. \& HESS, R.W.

1949 - Timbers of the New Worlds. New Haven, Yale Univ. Press. p. 551-552.

STAFLeU, F.A.

1953 - A monograph of the Vochysiaceae. III. Qualea. Acta Bot. Neerl, 2(2) $217 \mathrm{p}$. 